\title{
Antenatal Hydronephrosis
}

National Cancer Institute

\section{Source}

National Cancer Institute. Antenatal Hydronephrosis. NCI Thesaurus. Code C123155.

Hydronephrosis that occurs in a fetus. 